\title{
Síndrome de Klinefelter
}

Klinefelter Syndrome

\author{
Mayra Delgadillo-Hernández ${ }^{a}$,Erika G. Martínez-Arévalo ${ }^{a^{*}}$, Rubén Zamudio-Candelas ${ }^{a}$
}

\begin{abstract}
:
Klinefelter syndrome is a set of the most common metabolic and psychological chromosomal disorders in the male population affecting 1 in 500 men in the world. This disorder is present in all the cells of the organism affecting its chromosamas.

"This disorder is due to the presence of an extra X chromosome. 75\% of these individuals have a 47, XXY karyotype." This is a random error that occurs when any of the gametes are formed, either male or female.
\end{abstract}

\section{Keywords:}

Syndrome, chromosomal, organism, karyotype

\section{Resumen:}

El síndrome de Klinefelter es un conjunto de trastornos cromosómicos metabólicos y psicológicos más comunes en la población masculina afectando a 1 de cada 500 varones en el mundo. Este trastorno se encuentra presente en todas las células del organismo afectando a sus cromosomas.

"Este trastorno se debe a la presencia de un cromosoma X extra. Un 75\% de estos individuos tienen un cariotipo 47,XXY". Es un errror aleatorio que ocurre al formarse cualquiera de los gametos, ya sea masculino o femenino.

\section{Palabras Clave:}

Síndrome, cromosómicos, organismo y cariotipo

${ }^{a}$ Escuela Superior Tepeji del Rio, Licenciatura Médico Cirujano, Universidad Autónoma del Estado de Hidalgo, Av. del Maestro No.41, Col. Noxtongo $2^{\text {a }}$ Sección, Tepeji del Rio, Hidalgo, México, C.P. 42855. Email: *eri.arevmtz@gmal.com, mayraDelgadillo92@gmail.com ruben_s09@hotmail.com. 


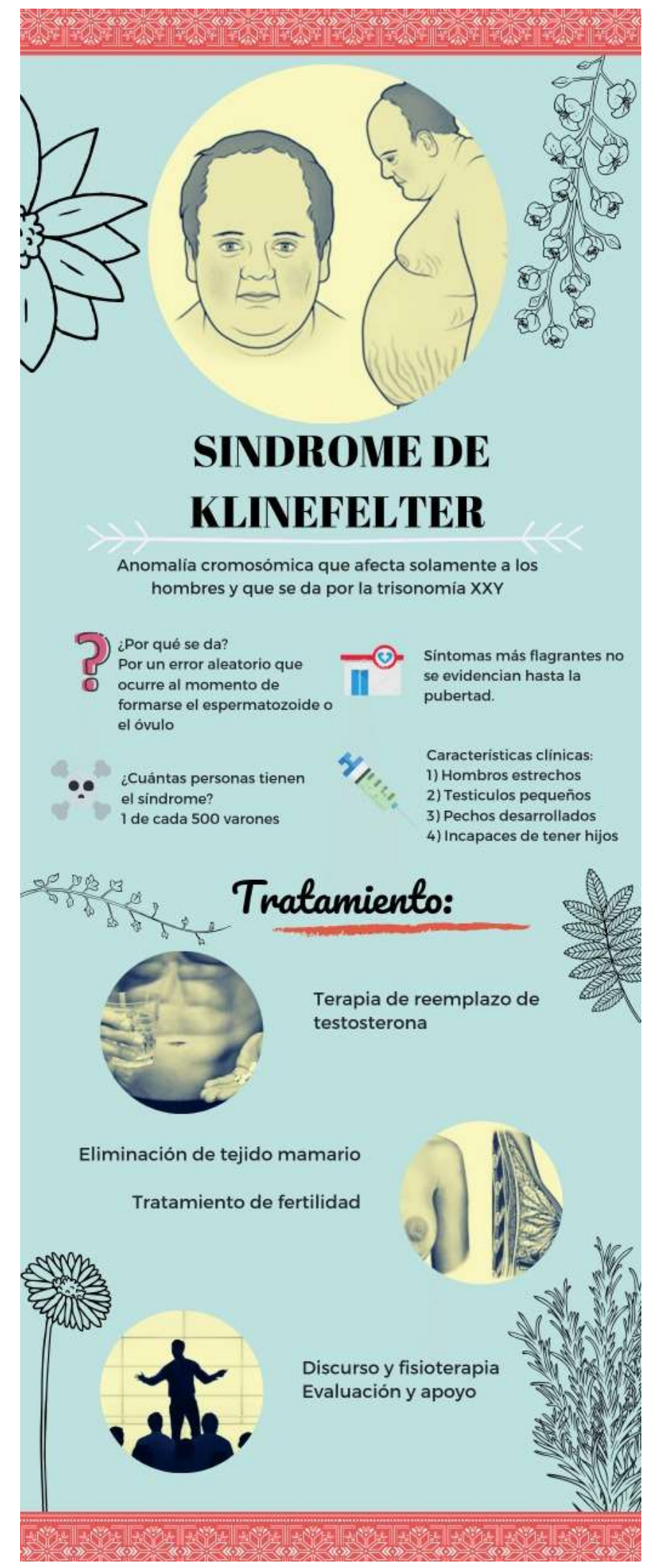

\section{Referencias}

[1] Juan P. López-Siguero (2018) Revista de Endocrinología: Sindrome de Klinefelter. https://www.endocrinologiapediatrica.org/revistas/P1E9/P1-E9-S300-A229.pdf

[2] Adrian Dobs, et al. (Mayo 2018) Hormone H.: Pacientes y cuidados del síndrome Klinelfelter.https://www.hormone.org/pacientes-ycuidadores/sindrome-de-klinefelter

[3] Mercé Artigas López (2019) Sindrome Klinefelter https://www.aeped.es/sites/default/files/documentos/8-klinefelter.pdf 